\title{
Adolescents Experiences with Respiratory Technology: A Phenomenological Study
}

\author{
Regena Spratling* \\ Assistant Professor, Child Health Pediatric Nurse Practitioner Program Coordinator, Byrdine F. Lewis School of Nursing and Health Professions, Georgia State \\ University, Atlanta, Georgia, USA
}

Received: May 10, 2016; Accepted: June 27, 2016; Published: July 01, 2016

*Corresponding author: Regena Spratling, Assistant Professor, Child Health Pediatric Nurse Practitioner Program Coordinator, Byrdine F. Lewis School of Nursing and Health Professions, Georgia State University, P.O. Box 4019, Atlanta, Georgia 30302-4019, USA, Tel: +404-413-1159 (office); Fax: +404-4131205; E-mail: rspratling@gsu.edu

\begin{abstract}
Purpose: The aim of the study was to explore the experiences of adolescents who require respiratory assistance.

Design and Methods: Data were collected in semi-structured interviews with eleven adolescents who required tracheostomies, with or without mechanical ventilator support, or ventilation via face mask.

Results and Conclusions: The adolescents were not focused on their daily need for technology. Their friends accepted them as a person, while others were felt to be judgmental. The adolescents did not know others who required respiratory or other technologies. Nurses can enhance care by fostering connections with other adolescents, including peers and adolescents who require technology.

Keywords: Adolescents/youth; Illness and disease; Chronic; Life-threatening/terminal; Research; qualitative; Qualitative analysis; Phenomenology
\end{abstract}

\section{Introduction}

In the last two decades, the population of adolescents who require technology to survive has grown considerably with advances in medical care and technology [1-4]. Many adolescents with chronic and life-threatening illnesses now live full, productive lives due to these advances in care and technology. Adolescents who require respiratory technology are a particularly vulnerable group among children who have complex chronic illnesses and special health care needs, often requiring technology and skilled care by nurses and caregivers $[1,3,5,6]$. Adolescents who depend on respiratory technology to maintain their health have a variety of chronic illnesses. Respiratory technology includes tracheostomies and ventilator support, either via tracheostomy or face mask (i.e., Bi-level Positive Airway Pressure [BiPap]). The technology needs may be intermittent or continuous throughout the day, and may include skilled care at home and school [5,712]. These adolescents may require respiratory technologies in addition to several other technologies.

Medically fragile children and adolescents have described the importance of school, peer relationships, and their perceptions of being normal $[7,10]$. However, studies to date have included both children and adolescents with a variety of medical diagnoses and technology needs. Further, most of the information on medically fragile adolescents has come from the adolescents' family rather than directly from the adolescents [13]. Thus, we know the parents' perspective, but not the adolescents' perspective. The experiences of adolescents who require respiratory technology, a specific technology with similarities in care needs and potential complications, have not been articulated.

These adolescents are a unique population with challenges in their daily lives; yet little is known about their experiences. This article examines the experiences of adolescents who require respiratory technology. Knowledge of the experiences of these adolescents can provide nurses with a better understanding of their needs and aid nurses in using the best approaches in caring for them. This knowledge can also provide insight with adolescents who experience chronic illness and have special health care needs.

\section{Design and Methods}

This study was part of a larger study of technology dependent adolescents which has been published elsewhere [13]. This study includes the same participants as the larger study, adolescents who require respiratory technology. The focus of the current study was on friendships and peer relationships as a secondary aim of the study. Specific aims were to gain knowledge of the daily lives of adolescents requiring respiratory technology, and the adolescents' experiences with friends, peers, and school.

Interpretive phenomenology guided the exploration of the adolescent participant experiences to reveal the meanings within experiences for these adolescents [14]. This method was chosen because phenomenology guides the exploration of a phenomenon through understanding of the participants' experiences [15]. For the current study, the phenomenon of interest was their experiences with respiratory technology. Interpretive phenomenology enhances the exploration of the adolescent's experiences, specifically who they think they are, how they walk through the world, how they relate to others, and 
how they experience daily life with respiratory technology. The daily experiences of these adolescents were conceptualized as taken-for-granted, meaning that these experiences are hidden to conscious thought [14]. While these experiences and their meanings are hidden to adolescents, they are also unique. Revealing these experiences can assist nurses in understanding what it is like to be an adolescent who requires respiratory technology and provide these adolescents better care based on their needs.

\section{Sample}

Participants were chosen based on their experiences with respiratory technology within the adolescent developmental stage. Respiratory technology was defined as tracheostomies and ventilator support, mechanical ventilation via tracheostomy or positive airway pressure support via face mask (i.e., Bilevel Positive Airway Pressure [BiPap]). The purposive sample included adolescents 13 to 18 years of age, male or female gender, and of any race or ethnicity. The sample size was determined by data saturation with 11 participants recruited for the study. The sample included 11 male $(n=5)$ or female $(n=6)$ adolescents who had a mean age of 15 years 8 months. Two were AfricanAmerican, seven were Caucasian, one was Hispanic, and one was both African-American and Caucasian. Their need for respiratory technology was similar (tracheostomy [ $\mathrm{n}=3]$, tracheostomy with mechanical ventilation [n=4], BiPap $[n=3]$ ) that if not used would be emergently detrimental to their health and potentially life-threatening. The single exception was one participant who had recently been decannulated (i.e., tracheostomy removed [n $=1]$ ). This participant had used respiratory technology on a daily basis prior to this time.

Participants were recruited from the outpatient Technology Dependent Pulmonary Clinic in a large pediatric hospital system and a private pediatric Pulmonology practice in the Southeastern United States. All participants met inclusion criteria of 1) using a minimum of one respiratory medical technology on a daily basis for the past 12 months or history of use of respiratory technology on a daily basis in the past two years, 2) the ability to understand and read English, and 3) the cognitive ability to answer questions without assistance from parents. Exclusion criteria included 1) adolescents with a diagnosis history of behavioral disorders and developmental disabilities, and 2) adolescents with a history of an extensive hospitalization, defined as greater than one month, in the last 6 months.

\section{Procedures}

After Institutional Review approvals were obtained, potential participants who met eligibility criteria were identified by providers and staff in a pediatric health care system outpatient clinic and private pediatric pulmonology office. The parents of potential participants were mailed a recruitment form which included information about the study for both the parent and the adolescent. Interested participants were instructed to contact the author by email or telephone for an in-person interview.

Prior to data collection, the purpose of the study, including risks and benefits, was discussed with the parent(s) and the adolescent. Written informed consent was obtained from the parent; written assent was obtained from the adolescent. The author then proceeded with data collection with the adolescent. Audio taped semi-structured interviews were conducted with the adolescent at their home, the clinic, or other settings that were comfortable for the adolescent.

The initial questions were asked specifically to establish rapport with the adolescent. For example, "Tell me about a time when you were doing something you really like to do. What are some of the other things you like to do? With friends? At home?" Subsequent questions explored daily life, school, future plans, and technology. For example, "How do you see yourself in the future? College? Relationships?" The final questions asked about advice for peers and nurses. For example, "What advice would you give to another adolescent with respiratory assistance? What advice can you give me to take care of an adolescent with respiratory assistance?" These questions were asked in related phenomenological studies with children and adolescents, revealing participant experiences and how nurses could better care for them $[13,16]$. One-time interviews required approximately 30 minutes of the participants time with a maximum of one hour allotted for interview.

\section{Data analysis}

The interviews were audio taped by the researcher and transcribed verbatim by a professional transcriptionist. The interview transcripts were reviewed while listening to the audio taped interview to ensure accuracy of the data by the researcher. Data analysis was completed by a team of researchers and doctoral students familiar with interpretive phenomenology, adolescent nursing care, and adolescent research. The research team assisted in the interpretation of meanings from the interview data and the presence of data saturation. Data analysis was completed using six steps outlined by Diekelmann, et al. [17] as this method guides interpretations and identifies shared meanings of the participants. In the first step, the interviews with adolescents were summarized by each member of the research team to gain an understanding of their experience and the interview as a whole. The second step consisted of reading the transcripts line by line and coding everything the participant said in the interview. The codes of the second interview were compared to the codes of the first interview, and so on, using the constant comparison method. The third step consisted of identifying meaningful phrases and words coded from the interviews and grouping those into categories. The categories were compared with those from the interviews with other adolescents, evaluating for similarities and differences. In the fourth step of the analysis, the team identified similar and contradictory categories and identified themes from the categories. In the fifth level, the research team identified emerging patterns in the interviews that reflected the relationships between the themes. In the final step, the themes were reviewed by the team to validate the interpretations.

\section{Trustworthiness}

Trustworthiness in the study was ensured in data collection 
and analysis using credibility, transferability, dependability, and confirmability as cited by Lincoln, et al. [18] for qualitative methods such as interpretive phenomenology. Credibility was ensured through member checking by validating the findings of the study from participants were validated with later with participants. Findings from the participants were presented using thick descriptions and quotes, allowing the reader to determine transferability to other adolescents. Dependability and confirmability were ensured through audio taped interviews that were transcribed verbatim and field notes and audit trail that recorded observations and methodological observations by the researcher [18].

\section{Results}

The adolescents viewed themselves as a person and were not focused on their daily need for technology. Friends accepted them for who they were as a person, while others were judgmental in the theme "My friends see me as a person, but others judge me. The adolescents were disconnected from other adolescents like them in regards to the need for respiratory technology or other technologies in the theme "The only one I know of". Pseudonyms are used to protect the identity of the participants.

"My friends see me as a person, but others judge me"

The adolescents described friends as being supportive. The adolescents felt that their friends did not care about their respiratory technology; however, they felt judged by those who were not their friends in the theme "My friends see me as a person, but others judge me". The adolescents' felt that their real friends were there for them, whereas those that were not their true friends were not. The adolescents felt that their friends, their true friends, were not concerned about their need for respiratory technology.

Ciara stated that her friends did not care that she had a tracheostomy. She stated “...I'm just a normal person who just has a trach. I think I'm just like everybody else...all my friends they don't care that I have a trach...they just see me as a normal person." Ciara felt that she was just like any other adolescent; she felt that her friends felt the same.

Brad described his friends' positive reaction to his respiratory technology. He described “...usually my friends are very open and receptive...I had my best friend over a few weeks ago and it was the first time he had saw my feeding tube and it didn't bother him at all..." He described his friends as understanding his need for respiratory and other technologies. They were accepting of him as a person.

These friends saw them for who they were, not their respiratory technology. This is how these adolescents viewed themselves. Their friends were described as "open and receptive" to their need for medical technology, which seems to differ from the sentiment from those not considered friends.

In contrast, the adolescents described feelings of being judged by others and being uncomfortable in situations with people that they did not know well. A common thread among these experiences was that they occurred with schoolmates who were not designated as friends to these adolescents.

Crystal described her feelings of being judged by schoolmates during a presentation at school. She stated " . . . I don't like speaking in front of class 'cus they just judge you more ... . like when I have to present a poster like I did today...people in the school just like, judge you more ... " Crystal recognized some schoolmates as not being friends and judging her appearance and behavior.

Ciara described her favorite time as "... Halloween ... because that's like the one day that you can be someone else and not get judged on it..." This was a time when she was not judged by others based on her need for respiratory technology, a visible presence for her that could be concealed with a Halloween costume. Ciara felt that others judged her, a contrast to previous statements that her friends do not care about her need for respiratory technology.

Stephanie described living with the tracheostomy. She noted “... when something's sticking out of your neck people are gonna notice and they're going to ask you about it." She described schoolmates as having questions about her tracheostomy. These schoolmates were not designated as friends, but as people that she was in contact with in her daily life. There was also a notion of judgment and questioning by those who do not know her well.

The adolescents conveyed experiences in which they felt judged by others, primarily schoolmates who were not considered friends. The subtheme "Others judge me" emphasizes their feelings of being uncomfortable around people that they do not know well and who do not understand the need for respiratory technology. This is in contrast to friends who support them and are there for them without concerns about their need for respiratory technology. The schoolmates who judged them did not know them as a person and see them as a person; they remained focused on their need for technology.

"The only one I know of"

These adolescents knew of others with similar needs for technology; however, few had friends and schoolmates that they interacted with on a regular basis. Stephanie described an adolescent with a tracheostomy at her school. She said "... I know this guy that goes to my school that has a trach ... but he's the only one that I know of that has like breathing issues at our school ..." This adolescent was the only other person who required respiratory technology like her, a tracheostomy. She referred to him as an acquaintance not someone with whom she was friends at school.

Ciara described an adolescent whom she used to know at school who had a tracheostomy like her. She remembered, "There was this one kid at school... he was like in a wheelchair ... he had a trach. He was a normal kid but his body couldn't function at all . .. he has a trach and I know him but... lost touch with him since he left school." The fact that he had a tracheostomy was an aside, a part of his being, not who he was as a person. Also of note, Ciara knew of him in general terms, but did not identify him as a friend 
or someone she knew well. He was the only person she knew of with a tracheostomy.

Michael described someone he knew with a tracheostomy. He said this adolescent "... who we've known since I was little ... he has a trach . . . but he's like, I guess the only one I know." He continued with ". . I've met him before but I think it was like . . . I don't remember or I don't remember him very well ..." Thus he knew about Peter, but did not actually know him. However, he did identify with the other adolescent's need for respiratory technology and described the adolescent as being like him.

Crystal knew others like her. She stated, "I have a best friend named Jennifer and she has muscular dystrophy too. She's the same age as me... and we've known each other since we were like five and we did dance together and she uses a BiPap ..." This friend was someone whom she saw as like her. The friend who required the same respiratory technology as she did was the only one she knew of, however, Randy, Rose, and Maya said that they did not know or know of any other adolescents who required respiratory technology. Maya did not know anyone else who required respiratory technology and she wondered whether anyone else existed. She asked the interviewer "Have you?" This question may suggest that the adolescents consider themselves the only people in their situation.

Few adolescents had friends like them that they knew well and interacted with on a regular basis. Most had an acquaintance at school that they knew of, but had little interaction with the other on a daily basis. They did not have anyone else like the min their world. They were "the only one I know of" in their experiences.

\section{Discussion}

The themes revealed from the data that the adolescents view themselves as a person, focusing on their daily lives, activities, and relationships; their focus is not on their daily need for technology. Their friends foster this view, while others views seem judgmental in the theme "My friends see me as a person, while others judge me". The theme, "The only one I know of" notes their lack of relationships with other adolescents who require technology.

\section{"My friends see me as a person, but others judge me"}

The adolescents felt that their friends saw them for who they really were as a person. This was in contrast to those that they did not consider friends who were perceived as judgmental. The focus of the adolescents was on the similarities that they had with friends. In turn, their friends recognized the adolescents as a person, not a person who requires respiratory technology.

Adolescence is a time when belonging is important and youth often exclude those who are different [19]. These adolescents focus on the things that make them similar to other adolescents, not the differences in requiring technology. This is contrasted in the theme "My friends see me as a person, but others judge me" in which the participants either felt accepted or judged. Beaune, et al. [20] found that adolescents with Treacher Collins, a craniofacial abnormality, were "reconstructing perceptions of others" through developing a positive sense of self-worth and helping others get to know them. The adolescents formed friendships that aided them in overcoming negative judgments from others [20]. Being judged by those not considered friends is a challenge for these adolescents and adolescents who have chronic illness. Support from friends helps adolescents overcome these challenges and develop positive self-esteem $[7,21]$.

The notion of friends as a supportive presence is found in this study and other studies on adolescents with chronic illness. Friendships are not a new concept for adolescents, but how friends are important is emerging into the concept of support from friends or social support for adolescents who require respiratory technology.

\section{"The only one I know of"}

The adolescent participants in this study had few connections with other adolescents like them. The majority had little acquaintance, if any, with others who required respiratory or other technologies. These adolescents did not know anyone like them with whom they could identify. This isolation and lack of connection to other like them was also found in a pilot study of the experiences of children with a tracheostomy [16].

One adolescent, Crystal, did have a friend who required respiratory and other technologies like her. This friend who required respiratory technology was a source of support for her and someone with whom she could identify with as having similar experiences. Kyngas [22] found that adolescents with chronic illnesses described peers who had chronic illnesses as "fellow sufferers" who understood and were caring and supportive of them. In the current study, only one adolescent knew someone that she could identify with as being supportive and understanding her experience.

Adolescents help one another by forming friendships and groups with others whom they identify with [19]. These adolescents did not have other adolescents like them. Previous studies with medically fragile children and adolescents have suggested that knowing children with similar concerns may be associated with higher self-esteem $[7,10]$. The findings from the current study support the view that having connections with other adolescents who require medical technologies is a concern for these adolescents.

\section{Limitations}

Limitations for the study included participant selection from a specific geographic location, associated developmental and communication problems in this population, and the parents' willingness to allow their adolescent's participation in the study. The sample was selected from a population of adolescents who require respiratory technology in the same geographic location. The presence of communication disorders and developmental delays often accompanying the need for respiratory technology also limited the sample. Lastly, parents were hesitant in allowing the adolescent to participate in the study until after they had carefully considered and discussed the study with their health care providers, the researcher, and the adolescent. 


\section{Conclusions}

This research was an initial step in the study of adolescents who require respiratory technology. Studies that explore other technologies and developmental stages would be helpful in increasing nursing knowledge. More studies are needed about this population to explore the best approaches to care by nurses and develop models of care based on their needs.

The adolescents lacked connections with other adolescents who required medical technology. Nurses can improve care by connecting with these adolescents and fostering friendships with other adolescents. Nurses can educate peers, schoolmates, and educators about chronic illness and the need for medical technology which may decrease barriers that exist among adolescents in building relationships and friendships. Nurses can also encourage the use of a "buddy system" in classes to foster connections with schoolmates for adolescents who may be hesitant to make connections. There is potential for development of online resources and "social networks" for adolescents within clinics, geographic areas, and on a national and international level. Knowing other adolescents who require respiratory technology and other technologies can help these adolescents find support and understanding from others like them.

Within the community and schools, education should be directed towards increasing awareness of adolescents who require respiratory technology and decreasing any myths or concerns that others may have, including peers, schoolmates, and educators. The adolescent participants noted that getting to know others and developing connections often alleviated others fears and concerns about their use of respiratory technology.

This study has contributed to the nursing knowledge of adolescents who require respiratory technology. This study also encompasses adolescents who require technology to assist them in their daily lives and adolescents with chronic illness. Through the adolescent participants' description of their experiences, insights have emerged for nurses who provide care to them. In uncovering their needs, there is an opportunity for enhancing nursing care for all adolescents. These adolescents have a positive view of technology and do not focus on their daily need for technology; their focus is on daily living, being their own person, and friendships. Nurses can ask about their daily lives and focus on the adolescents, not their need for respiratory technology as a vital part of nursing care. Nurses can also assist with networking adolescents who require respiratory technology and other technologies, in addition to fostering relationships with peers and schoolmates. Through these actions, nurses foster self-esteem and encourage independence in daily living for these adolescents.

\section{Declarations}

\section{Conflict of Interest}

NA; there is no conflicts of interest.

\section{Ethical Approval}

Approval for this study was obtained through the Institutional
Review Boards of Children's Healthcare of Atlanta and Georgia State University, CHOA \#08-007.

\section{Clinical trial registration}

This was not a clinical trial, however, fully informed written consent and assent was obtained.

\section{Funding}

The author disclosed receipt of the following financial support for the research, authorship, and/or publication of this article. This research was funded by the Epsilon Alpha Chapter of Sigma Theta Tau International.

\section{References}

1. Buescher PA, Whitmire JT, Brunssen S, Kluttz-Hile CE. Children who are medically fragile in North Carolina: Using Medicaid data to estimate prevalence and medical care costs in 2004. Matern Child Health J. 2006;10(5):461-6.

2. Carnevale FA, Rehm RS, Kirk S, McKeever P. What we know (and do not know) about raising children with complex continuing care needs. J Child Health Care. 2008;12(1):4-6. doi: 10.1177/1367493508088552.

3. Child and Adolescent Health Measurement Initiative (2011). Data Resource Center on Child and Adolescent Health. Retrieved March 20, 2013 from http://childhealthdata.org/learn/NS-CSHCN

4. Simon TD, Berry J, Feudtner C, Stone BL, Sheng X, Bratton SL, et al. Children with complex chronic conditions in inpatient hospital settings in the United States. Pediatrics. 2010;126(4):647-55. doi: 10.1542/peds.2009-3266.

5. Lindahl B, Lindblad BM. Being the parent of a ventilator-assisted child: Perceptions of the family-health care provider relationship when care is offered in the family home. J Fam Nurs. 2013;19(4):489-508. doi: $10.1177 / 1074840713506786$.

6. Russell CJ, Simon TD. Care of children with medical complexity in the hospital setting. Pediatr Ann. 2014;43(7):e157-62. doi: 10.3928/00904481-20140619-09.

7. Earle RJ, Rennick JE, Carnevale FA, Davis GM. 'It's okay, it helps me to breathe': The experience of home ventilation from a child's perspective. J Child Health Care. 2006;10(4):270-82.

8. Haley J, Ratliffe C. Application of the Integrative Harmony Paradigm and Model. Issues Compr Pediatr Nurs. 2006;29(1):53-68.

9. Harrigan RC, Ratliffe C, Patrinos ME, Tse A. Medically fragile children: An integrative review of the literature and recommendations for future research. Issues Compr Pediatr Nurs. 2002;25(1):1-20.

10. Heaton J, Noyes J, Sloper P, Shah R. Families' experiences of caring for technology-dependent children: a temporal perspective. Health Soc Care Community. 2005;13(5):441-50.

11. Rehm RS, Bradley JF. Normalization in families raising a child who is medically fragile/technology dependent and developmentally delayed. Qual Health Res. 2005;15(6):807-20.

12. Rehm RS, Rohr JA. Parents', nurses', and educators' perceptions of risks and benefits of school attendance by children who are medically fragile/technology-dependent. J Pediatr Nurs. 2002;17(5):345-53.

13. Spratling R. The experiences of medically fragile adolescents who require respiratory assistance. J Adv Nurs. 2012;68(12):2740-9. doi: 10.1111/j.1365-2648.2012.05979.x. 
14. Heidegger M. Being and time. New York: Harper \& Row. 1962.

15. Benner P. Introduction. Interpretive phenomenology: Embodiment, caring, and ethics in health and illness. Thousand Oaks: Sage Publications. 1994.

16. Spratling R, Minick P, Carmon M. The experiences of school-age children with a tracheostomy. J Pediatr Health Care. 2012;26(2):11825. doi: 10.1016/j.pedhc.2010.07.005.

17. Diekelmann N, Allen D, Tanner CA. A hermeneutic analysis of the NLN criteria for the appraisal of baccalaureate programs : The NLN criteria for appraisal of baccalaureate programs: A Critical Hermeneutic Analysis. New York: National League for Nursing. 1989.

18. Yvonna S. Lincoln, Egon G. Guba. Naturalistic inquiry. Newbury Park, CA: Sage Publications, Inc. 1985.
19. Erik Homburger Erikson. Childhood and society ( $2^{\text {nd }}$ ed.). New York: W. W. Norton \& Company. 1963.

20. Beaune L, Forrest CR, Keith T. Adolescents' perspectives on living and growing up with Treacher Collins syndrome: A qualitative study. Cleft Palate Craniofac J. 2004;41(4):343-50.

21. Tarrant M, MacKenzie L, Hewitt LA. Friendship group identification, multidimensional self-concept, and experience of developmental tasks in adolescence. J Adolesc. 2006;29(4):627-40.

22. Kyngäs H. Support network of adolescents with chronic disease: Adolescents' perspective. Nurs Health Sci. 2004;6(4):287-93. 